\title{
Reconsolidation of appetitive memories for both natural and drug reinforcement is dependent on $\boldsymbol{\beta}$-adrenergic receptors
}

\author{
Amy L. Milton, ${ }^{1,2}$ Jonathan L.C. Lee, ${ }^{1,2}$ and Barry J. Everitt \\ Behavioural and Clinical Neuroscience Institute, Department of Experimental Psychology, University of Cambridge, Downing Site, \\ Cambridge CB2 3EB, United Kingdom
}

\begin{abstract}
We have investigated the neurochemical mechanisms of memory reconsolidation and, in particular, the functional requirement for intracellular mechanisms initiated by $\beta$-adrenergic signaling. We show that propranolol, given in conjunction with a memory reactivation session, can specifically disrupt the conditioned reinforcing properties of a previously appetitively reinforced conditioned stimulus (CS), whether the stimulus had been associated with self-administered cocaine or with sucrose. These data show that memories for both drug and nondrug CS-US associations are dependent on $\boldsymbol{\beta}$-adrenergic receptor-mediated signaling for their reconsolidation, with implications for the potential development of a novel treatment for drug addiction and some forms of obesity.
\end{abstract}

The neurochemical mechanisms underlying memory reconsolidation-the process hypothesized to occur following the reactivation or retrieval of a fully consolidated memory upon reexposure to conditioned stimuli (Nader 2003; Dudai and Eisenberg 2004)—have become increasingly investigated, in part because of the emergence of the view that disrupting memory reconsolidation might be exploited to treat neuropsychiatric disorders based upon the existence of maladaptive memories (e.g., Debiec and LeDoux 2006).

Adrenergic signaling is implicated in both memory consolidation and reconsolidation; the administration of adrenaline enhances memory consolidation in aversive and appetitive tasks in animals and humans (Gold et al. 1977; Liang et al. 1985; Sternberg et al. 1985; Introini-Collison and McGaugh 1986), and the administration of adrenergic receptor antagonists induces memory deficits in tasks including inhibitory avoidance (Lennartz et al. 1996), taste memory (Miranda et al. 2003), and odor-reward associations (Wilson et al. 1994) in rats and, in humans, fear memory (Grillon et al. 2004) and emotional learning (Cahill et al. 1994; van Stegeren et al. 1998). In rodents, $\beta$ adrenergic signaling has also been implicated in the reconsolidation of CS-fear memories (Debiec and LeDoux 2004), drugassociated memories (Bernardi et al. 2006), spatial memories (Przybyslawski et al. 1999), and other forms of appetitive memory (Diergaarde et al. 2006). However, although the administration of $\beta$-adrenergic receptor antagonists has been shown to disrupt appetitive memories in both a cocaine-conditioned place preference (Bernardi et al. 2006) and a context-induced sucroseseeking task (Diergaarde et al. 2006), it remains unclear whether CS-food memories undergo reconsolidation in a similar manner to CS-addictive drug associations.

It has been proposed that drug-associated memories may be mediated by the same neural and psychological mechanisms as memories resultant on conditioning to natural rewards (Robbins and Everitt 2002; Kelley 2004). For example, the acquisition of responding for cocaine- and sucrose-paired conditioned reinforc-

\footnotetext{
1These authors contributed equally to this work.

${ }^{2}$ Corresponding authors.

E-mail alm46@cam.ac.uk; fax 44-1223-333564.

E-mail jlcl2@cam.ac.uk; fax 44-1223-333564.

Article is online at http://www.learnmem.org/cgi/doi/10.1101//m.825008.
}

ers is topographically similar, and both are equally persistent (Grimm et al. 2001, 2005; Di Ciano and Everitt 2004). Therefore, we have employed an acquisition of a new instrumental response with conditioned reinforcement (ANR) procedure to investigate further the pharmacological mechanisms of appetitive memory reconsolidation, using the $\beta$-adrenergic receptor antagonist propranolol as a putative amnestic agent, with both natural (sucrose) and drug (cocaine) reinforcers. This we did in order to compare directly the neuropharmacological mechanisms underlying the reconsolidation of Pavlovian associations between environmental conditioned stimuli (CSs) and appetitive reinforcers (unconditioned stimuli, or USs). This has both theoretical and potentially translational implications, as some forms of obesity have been suggested to be analogous to an addiction to "comfort foods," with food craving, like drug craving, being elicited by presentation of associated CSs (Grant et al. 1996; Wang et al. 2004; Volkow and Wise 2005). Therefore, investigating whether the reconsolidation of CS-US memories for natural and addictive drug reinforcers are dependent upon common neurochemical mechanisms may also allow the development of reconsolidationbased treatments for both drug addiction and obesity.

Male Lister Hooded rats were trained and tested on the ANR procedure as described previously for the intravenous (i.v.) cocaine condition (Lee et al. 2005). Briefly, in the sucrose condition, rats were conditioned to perform a nosepoke response to receive a $1.0-\mathrm{mL} 10 \%$ liquid sucrose reinforcement, paired with a 10 -sec light CS. All groups acquired the nosepoke response for sucrose reinforcement, and the total number of CS-sucrose pairings was similar across all groups (data not shown; group means between 264 and 267.9 pairings; Treatment: $F<1$; Reactivation, $F<1$; Treatment $\times$ Reactivation: $F_{(1,32)}=2.86$, not significant [ns]). Importantly, therefore, conditioning of the CS-sucrose association was equivalent in all groups. The CS-sucrose association was then reactivated in a 10-min Pavlovian extinction session, in which only the CS and not sucrose reinforced the nosepoke response. During this session the groups received similar numbers of non-reinforced CS exposures (data not shown; saline $=22.7 \pm 1.3$, propranolol $=22.2 \pm 1.3$ ), as shown by an independent-samples $t$-test $\left(t_{(18)}=0.29\right.$, ns). Therefore, there were no differences between the groups in conditioning, CS exposure, or extinction.

The conditioned reinforcing properties of the sucrose- 
associated CS were then tested by its ability to support the acquisition of a new lever-press response as described previously (Lee et al. 2005). As the variance of lever pressing increases with the mean (Winer 1991), thus violating the homogeneity of variance assumption of ANOVA, the data were square-roottransformed for statistical analysis. However, to facilitate interpretation, the raw data are presented in the figures. Administration of the $\beta$-adrenergic receptor antagonist DL-propranolol hydrochloride (10 mg/kg; Sigma-Aldrich), immediately following the reactivation session, resulted in a reactivation-dependent impairment in the acquisition of a new instrumental sucroseseeking response measured subsequently. The reactivated control saline group learned to respond on the active lever for the CS over the four sessions of acquisition, and responding was significantly higher than on the inactive lever (Fig. 1A). In contrast, the reactivated propranolol group made many fewer responses on the active lever than control rats. Moreover, rats injected with propranolol showed no preference for the active lever over the inactive lever for up to $8 \mathrm{~d}$ after reactivation. The impairments in the acquisition of a new response were critically dependent upon reactivation of the CS-sucrose memory, since rats that were injected with propranolol, but with the memory reactivation session omitted, readily learned the new instrumental response with

A

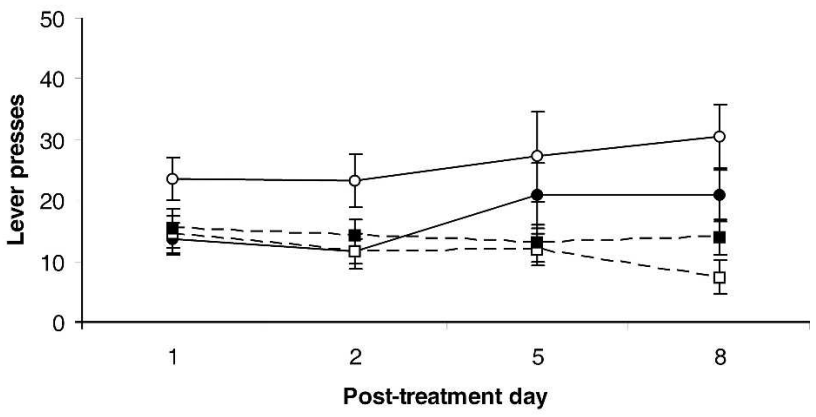

$\multimap$ VAL $\longrightarrow P A L--\square-V I L-\rightarrow-P I L$

B

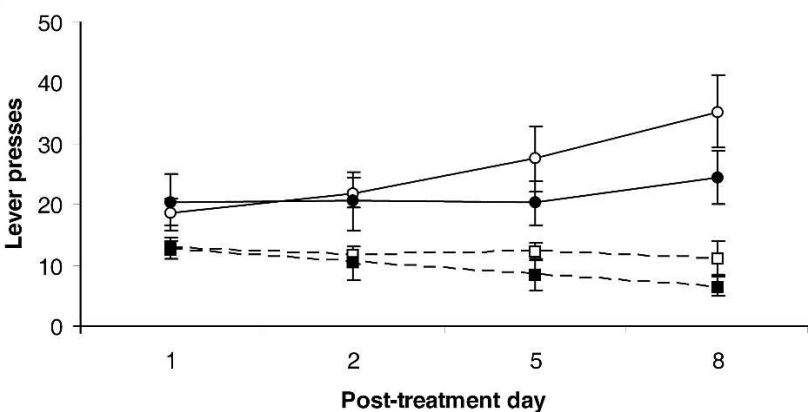

$\longrightarrow-\mathrm{VAL} \longrightarrow \mathrm{PAL}--\mathrm{a}-\mathrm{VIL}-\rightarrow-\mathrm{PIL}$

Figure 1. Test data for Experiment 1. Administration of propranolol immediately following memory reactivation impaired the reconsolidation of a CS-sucrose memory, as measured by the acquisition of a new instrumental response for conditioned reinforcement. Active and inactive leverpress responses were compared over four test sessions, conducted on post-reactivation days $1,2,5$, and 8 for both reactivated $(A)$ and nonreactivated $(B)$ groups (Treatment $\times$ Reactivation $\times$ Lever, $F_{(1,32)}=9.15$, $P<0.01$; Treatment $\times$ Reactivation $\times$ Lever $\times$ Session, $F<1$; Treatment $\times$ Reactivation, $F<1$ ). VAL, vehicle, active lever; PAL, propranolol, active lever; VIL, vehicle, inactive lever; PIL, propranolol, inactive lever. Propranolol-treated rats did not respond more on the active than the inactive lever (Lever, $F<1$; Lever $\times$ Session, $F_{(2,17)}=3.12$, ns). Data are presented as mean \pm SEM, $n=8-10$ per group. conditioned reinforcement. Saline- and propranolol-treated rats in the non-reactivated condition thus showed a strong preference for the active lever over the inactive lever (Fig. 1B). An overall comparison of reactivated and non-reactivated groups revealed a reactivation-dependent effect of treatment upon discriminated responding across all four test sessions, which indicates a persistent impairment in learning the new response.

Importantly, there was no difference between the groups in overall (inactive and active) lever-pressing activity or nosepoke responses during the test sessions (data not shown; Reactivation $\times$ Treatment, $P>0.06$; Reactivation $\times$ Treatment $\times$ Session, $P>0.10$ ), which reveals that there was no deficit in general motivation or activity. Furthermore, the reactivation dependence of the impairment demonstrates that propranolol had no nonspecific effects on leverpressing performance.

Administration of propranolol also resulted in a reactivation-dependent impairment in the acquisition of a new response for cocaine-conditioned reinforcement (for methods, see Lee et al. 2005). To facilitate the comparison with the sucrose experiment, the data are first presented and initially analyzed for the first four sessions only (Fig. 2A,B). As before, the data were square-roottransformed for statistical analysis so that the homogeneity of variance assumption of ANOVA would not be violated. The reactivated, saline-treated group learned to respond preferentially on the active lever for the CS over the four sessions of acquisition, and active lever responding was significantly higher than on the inactive lever (Fig. 2A). However, the reactivated, propranolol-treated group did not discriminate between the active and inactive levers, indicating that the conditioned reinforcing properties of the CS had been abolished. This impairment in responding for conditioned reinforcement was reactivation-dependent, since the non-reactivated, propranolol-treated group was unimpaired compared to control (Fig. 2B).

The persistence of the impairment in responding for conditioned reinforcement was investigated by measuring responding on a further three test sessions, conducted at weekly intervals (post-reactivation days 15, 22, and 29; Fig. 2C,D). Analysis of all seven post-reactivation test sessions supported the previous analysis, with only the reactivated, propranolol-treated group showing a reactivation-dependent impairment in responding for conditioned reinforcement. Although the reactivated, propranolol-treated group discriminated between the active and inactive levers during these subsequent test sessions, there was still a marked impairment in active lever responding compared to the reactivated, vehicle-treated group. Therefore these data fulfill the criteria for a memory reconsolidation-induced deficit (Dudai 2004), namely, that of a reactivation-dependent and persistent impairment.

Prior to the cocaine-conditioned reinforcement test, all groups acquired the nosepoke response for i.v. cocaine reinforcement, and the total number of CS-cocaine pairings was similar across all groups. There were no differences between the prospective propranolol and vehicle rats in terms of the CS-cocaine pairings experienced (data not shown; group means between 235.3 and 268.1 pairings; Treatment, $F<1$; Reactivation, $F<1$; Treatment $\times$ Reactivation, $F_{(1,24)}=2.23$, ns). Both of the reactivated groups received similar numbers of unreinforced CS exposures during the 15 -min memory reactivation session (data not shown; saline $=18.0 \pm 1.18$, propranolol $=17.0 \pm 1.58)$ as shown by an independent-samples $t$-test $\left(t_{(14)}=0.68, \mathrm{~ns}\right)$.

Injections of propranolol did not induce a negative affective or motivational state sufficient to condition a place aversion (Fig. 3 ), suggesting that the effects of propranolol in the ANR experiments were not due to counterconditioning to the CS or to any aversive effects of the propranolol treatment. 
The results of these experiments demonstrate that discrete appetitive Pavlovian associations reinforced by both natural (sucrose) and drug (cocaine) rewards undergo reconsolidation after memory reactivation by CS presentation. They furthermore show that systemic injections of the $\beta$-adrenergic receptor antagonist DL-propranolol can disrupt the reconsolidation of both CS-drug
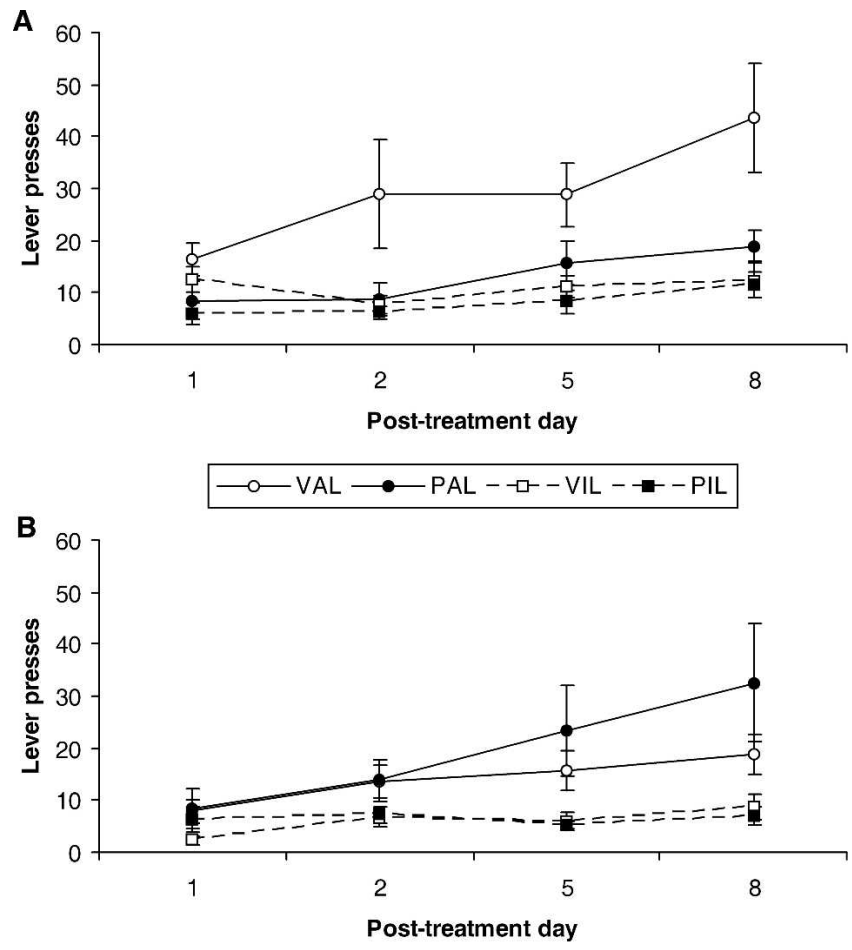

$\multimap$ VAL $\longrightarrow$ PAL $--\square--V I L-\rightarrow--P I L$
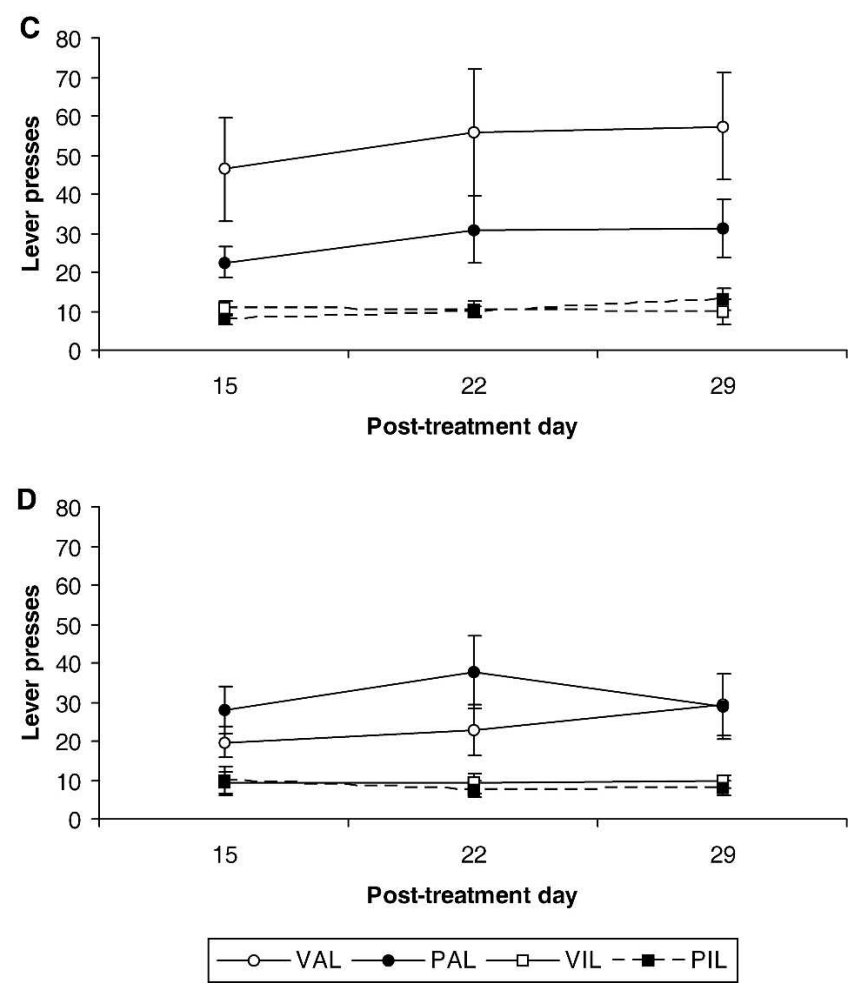

and CS-sucrose memories. Administration of propranolol, immediately following a CS-evoked memory reactivation session, dramatically impaired the ability of both a previously sucrose-paired CS and a previously cocaine-paired CS to support the acquisition of a new instrumental response when tested days after the propranolol treatment. The selective deficit in active lever responding reflects an attenuation of the conditioned reinforcing properties of the appetitive CS and cannot be attributed to a decrease in overall activity. Importantly, the impairment in instrumental responding for conditioned reinforcement seen in the propranolol-treated, reactivated groups was critically dependent upon the retrieval of the memory by CS presentation at the time of propranolol administration, since propranolol had no effect when given without reactivation of either the CS-sucrose or the CS-drug memory. The deficit was persistent, lasting for at least 8 $\mathrm{d}$ for the previously sucrose-paired CS and for $29 \mathrm{~d}$ for the previously cocaine-paired CS. The persistence and reactivationdependence of the propranolol-induced amnesia fulfill the necessary criteria for a disruption of memory reconsolidation (Dudai 2004), and so these data suggest that propranolol, when given in conjunction with a memory reactivation session, can impair the reconsolidation of appetitive CS-US memories and thereby reduce the ability of previously appetitive CSs to control subsequent instrumental behavior. Furthermore, as post-reactivation propranolol results in a complete elimination of the conditioned reinforcing properties of cocaine- and sucrose-associated stimuli, this provides further evidence that addictive drug and natural reward-related memories are mediated by similar or overlapping mechanisms (Robbins and Everitt 2002; Kelley 2004).

An alternative explanation for the decrease in instrumental responding for conditioned reinforcement-that the propranolol injection might have led to a conditioned aversion, thus indirectly opposing the conditioned reinforcing properties of the previously drug-paired CS - can be discounted, because we have demonstrated that a single injection of propranolol does not induce a central aversive state capable of supporting acquisition of a conditioned place aversion. Thus, it is unlikely that propranolol reduced subsequent lever pressing because of the acquisition of an aversive "CS-propranolol" association by the reactivated, propranolol-treated rats.

The results of these experiments are consistent with previous suggestions of a role for adrenergic signaling in memory reconsolidation, as propranolol has been shown to disrupt the reconsolidation of spatial memories (Przybyslawski et al. 1999) and conditioned fear memories (Debiec and LeDoux 2004). Our results also complement, and significantly extend, those of Bernardi et al. (2006) and Diergaarde et al. (2006). Bernardi et al. (2006) showed that propranolol, given at the same dose and route of administration used here, disrupted the reconsolidation

Figure 2. Test data for Experiment 2. Propranolol administered immediately following memory reactivation attenuated the conditioned reinforcing properties of a previously cocaine-paired CS, as measured by the acquisition of a new instrumental response on post-reactivation days $1,2,5$, and 8 , for $(A)$ reactivated but not $(B)$ non-reactivated groups (Treatment $\times$ Reactivation, $F_{(1,24)}=6.10, P<0.05$ Treatment $\times$ Reactivation $\times$ Session, $F<1)$. VAL, vehicle, active lever; $\mathrm{PAL}$, propranolol, active lever; VIL, vehicle, inactive lever; PIL, propranolol, inactive lever. Propranolol-treated rats did not respond more on the active than the inactive lever (Lever, $F_{(1,8)}=2.30$, ns; Lever $\times$ Session, $\left.F_{(1.94,15.5)}=1.40, \mathrm{~ns}\right)$. Extended testing of these rats revealed that the impairment in responding for conditioned reinforcement persisted for at least $29 \mathrm{~d}$ following the memory reactivation session when propranolol was given in conjunction with a memory reactivation session (C) but not when the reactivation session was omitted $(D)$ (analysis for all seven test sessions; Reactivation $\times$ Treatment, $F_{(1,24)}=4.41, P<0.05$; Treatment $\times$ Reactivation $\times$ Session, $F<1)$. Data are presented as mean \pm SEM, $n=5-9$ per group. 


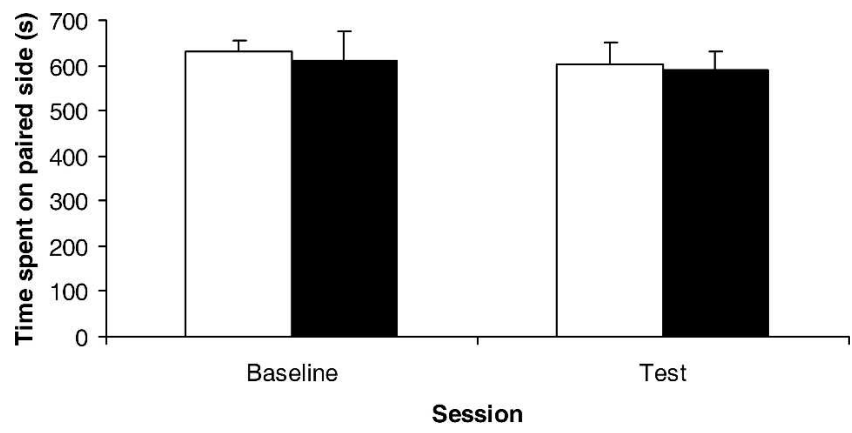

$\square$ Vehicle Propranolol

Figure 3. Propranolol injection was not itself aversive, as a place aversion could not be conditioned to the injection. Rats were habituated to a two-compartment apparatus (baseline), $24 \mathrm{~h}$ before an injection of propranolol was paired with one of the compartments (counterbalanced); 24 $\mathrm{h}$ following the pairing session, the rats were assessed for the time spent on each side of the apparatus. As the time spent on the paired and unpaired sides was not independent, only data for the paired side is presented here. The time spent on the injection-paired side of a twocompartment apparatus did not change between the preconditioning habituation session and the postconditioning test. There was no main effect of Treatment $(F<1$, ns) and no significant interaction (Treatment $\times$ Session, $F<1$, ns). Data are presented as mean $\pm S E M$, $n=4-8$ per group.

of a conditioned place preference (CPP) memory for cocaine. However, a critical procedural difference between the study by Bernardi et al. (2006) and the present study is that in the CPP procedure, rats were given only four experimenter-administered i.p. injections of cocaine, while in the present experiment cocaine was extensively self-administered (180-270 infusions over $9 \mathrm{~d}$ ), resulting in more robust CS-drug associative conditioning. Therefore, the current procedure perhaps more closely models the situation seen in drug addiction in humans, since cocaine was self-administered intravenously for a considerable period of time (see also Lee et al. 2005, 2006). It also provides a clear demonstration of CS-drug memory disruption at reactivation, as the new instrumental response could only have been learned if the previously drug-paired CS had retained its affective or motivational properties to act as a conditioned reinforcer. By contrast, neither the nature of the association that is targeted by disrupting reconsolidation in the CPP procedure nor how disrupted CPP relates to the instrumental acts of drug seeking and taking is clear. Thus, CPP may reflect the expression of an instrumental association (rats moving to the paired environment in order to receive drug injections), an automatic Pavlovian approach response to a drug-associated CS, or reward expectancy (for a discussion of the CPP procedure, see Everitt and Robbins 1992 and Schechter and Calcagnetti 1993). Moreover, it is unclear whether rats are conditioned to elemental (discrete) cues or configural contexts when acquiring CPP (Ito et al. 2006).

The ANR procedure, by contrast, isolates and tests the conditioned reinforcing property of a discrete appetitive stimulus (Mackintosh 1974; Di Ciano and Everitt 2004), which, in an addictive drug setting, is known to be of critical importance in supporting or inducing drug seeking (See et al. 1999; Crombag and Shaham 2002; Di Ciano and Everitt 2004). Furthermore, it is known that the acquisition of a new instrumental response is not supported solely by the sensory properties of a stimulus, since rats are unable to learn the new instrumental response for a CS that is novel or explicitly unpaired with reward during training (Taylor and Robbins 1984; Parkinson et al. 2005). It remains to be determined, however, whether propranolol given at memory retrieval also impacts upon contextual influences on drug seeking as well as sucrose seeking measured subsequently, as studied, for example, in renewal procedures (e.g., Crombag and Shaham 2002).

The results of the present experiments demonstrate that appetitive Pavlovian memories for stimuli associated with both natural and addictive drug reinforcers undergo memory reconsolidation following retrieval and that these reconsolidation mechanisms are commonly dependent on adrenergic signaling. Moreover, impairing reconsolidation has a long-term impact, disrupting instrumental responding at test long after the reactivation treatment session. As CSs previously associated with drug have been shown to be associated with drug craving in human addicts (Grant et al. 1996; Childress et al. 1999; Garavan et al. 2000; Kilts et al. 2001; Bonson et al. 2002) and to precipitate relapse in animal models of addiction (de Wit and Stewart 1981; Shaham et al. 2003), these results suggest that propranolol, given in conjunction with a memory reactivation session in humans, may act as a pro-abstinence/anti-relapse treatment for drug addiction. Furthermore, as drug addiction and some forms of obesity have been hypothesized to depend upon common underlying neurobiological and psychological mechanisms (Wang et al. 2004; Kelley et al. 2005; Volkow and Wise 2005; Rothemund et al. 2007), this may suggest that a reconsolidation-based treatment using propranolol could also be useful in reducing cueinduced craving for "comfort foods."

\section{Acknowledgments}

This work was supported by the United Kingdom Medical Research Council (MRC) Programme (grant no. 9536855) and was conducted within the MRC/Wellcome Trust Behavioural and Clinical Neuroscience Institute. A.L.M. was financially supported by a MRC research studentship and by Newnham College, Cambridge.

\section{References}

Bernardi, R.E., Lattal, K.M., and Berger, S.P. 2006. Postretrieval propranolol disrupts a cocaine conditioned place preference. NeuroReport 17: 1443-1447.

Bonson, K.R., Grant, S.J., Contoreggi, C.S., Links, J.M., Metcalfe, J., Weyl, H.L., Kurian, V., Ernst, M., and London, E.D. 2002. Neural systems and cue-induced cocaine craving. Neuropsychopharmacology 26: $376-386$.

Cahill, L., Prins, B., Weber, M., and McGaugh, J.L. 1994. $\beta$-Adrenergic activation and memory for emotional events. Nature 371: 702-704

Childress, A.R., Mozley, P.D., McElgin, W., Fitzgerald, J., Reivich, M., and O'Brien, C.P. 1999. Limbic activation during cue-induced cocaine craving. Am. J. Psychiatry 156: 11-18.

Crombag, H.S. and Shaham, Y. 2002. Renewal of drug seeking by contextual cues after prolonged extinction in rats. Behav. Neurosci. 116: $169-173$.

de Wit, H. and Stewart, J. 1981. Reinstatement of cocaine-reinforced responding in the rat. Psychopharmacology 75: 134-143.

Debiec, J. and LeDoux, J.E. 2004. Disruption of reconsolidation but not consolidation of auditory fear conditioning by noradrenergic blockade in the amygdala. Neuroscience 129: 267-272.

Debiec, J. and LeDoux, J.E. 2006. Noradrenergic signaling in the amygdala contributes to the reconsolidation of fear memory: Treatment implications for PTSD. Ann. N.Y. Acad. Sci. 1071: 521-524.

Di Ciano, P. and Everitt, B.J. 2004. Conditioned reinforcing properties of stimuli paired with self-adminstered cocaine, heroin or sucrose: Implications for the persistence of addictive behavior. Neuropharmacology 47: 202-213.

Diergaarde, L., Schoffelmeer, A.N.M., and De Vries, T.J. 2006. $\beta$-Adrenoreceptor mediated inhibition of long-term reward-related memory reconsolidation. Behav. Brain Res. 170: 333-336.

Dudai, Y. 2004. The neurobiology of consolidations, or, how stable is the engram? Annu. Rev. Psychol. 55: 51-86.

Dudai, Y. and Eisenberg, M. 2004. Rites of passage of the engram: Reconsolidation and the lingering consolidation hypothesis. Neuron 44: $93-100$.

Everitt, B.J. and Robbins, T.W. 1992. Amygdala-ventral striatal interactions and reward-related processes. In The amygdala: 
Neurobiological aspects of emotion, memory, and mental dysfunction (ed. J.P. Aggleton), pp. 401-429. Wiley-Liss, New York.

Garavan, H., Pankiewicz, J., Bloom, A., Cho, J.-K., Sperry, L., Ross, T.J., Salmeron, B.J., Risinger, R., Kelley, D., and Stein, E.A. 2000. Cue-induced cocaine craving: Neuroanatomical specificity for drug users and drug stimuli. Am. J. Psychiatry 157: 1789-1798.

Gold, P.E., van Buskirk, R., and Haycock, J.W. 1977. Effects of posttraining epinephrine injections on retention of avoidance training in mice. Behav. Biol. 20: 197-204.

Grant, S., London, E.D., Newlin, D.B., Villemagne, V.L., Liu, X., Contoreggi, C., Phillips, R.L., Kimes, A.S., and Margolin, A. 1996. Activation of memory circuits during cue-elicited cocaine craving. Proc. Natl. Acad. Sci. 93: 12040-12045.

Grillon, C., Cordova, J., Morgan, C.A., Charney, D.S., and Davis, M. 2004. Effects of the beta-blocker propranolol on cued and contextual fear conditioning in humans. Psychopharmacology 175: 342-352.

Grimm, J.W., Hope, B.T., Wise, R.A., and Shaham, Y. 2001. Incubation of cocaine craving after withdrawal. Nature 412: 141-142.

Grimm, J.W., Fyall, A.M., and Osincup, D.P. 2005. Incubation of sucrose craving: Effects of reduced training and sucrose pre-loading. Physiol. Behav. 84: 73-79.

Introini-Collison, I. and McGaugh, J.L. 1986. Epinephrine modulates long-term retention of an aversively motivated discrimination. Behav. Neural Biol. 45: 358-365.

Ito, R., Robbins, T.W., McNaughton, B.L., and Everitt, B.J. 2006. Selective excitotoxic lesions of the hippocampus and basolateral amygdala have dissociable effects on appetitive cue and place conditioning based on path integration in a novel Y-maze procedure. Eur. J. Neurosci. 23: 3071-3080.

Kelley, A.E. 2004. Memory and addiction: Shared neural circuitry and molecular mechanisms. Neuron 44: 161-179.

Kelley, A.E., Schiltz, C.A., and Landry, C.F. 2005. Neural systems recruited by drug- and food-related cues: Studies of gene activation in corticolimbic regions. Physiol. Behav. 86: 11-14.

Kilts, C.D., Schweitzer, J.B., Quinn, C.K., Gross, R.E., Faber, T.L., Muhammad, F., Ely, T.D., Hoffman, J.M., and Drexler, K.P.G. 2001 Neural activity related to drug craving in cocaine addiction. Arch. Gen. Psychiatry 58: 334-341.

Lee, J.L.C., Di Ciano, P., Thomas, K.L., and Everitt, B.J. 2005. Disrupting reconsolidation of drug memories reduces cocaine seeking behavior. Neuron 47: 795-801.

Lee, J.L.C., Milton, A.L., and Everitt, B.J. 2006. Cue-induced cocaine seeking and relapse are reduced by disruption of drug memory reconsolidation. J. Neurosci. 26: 5881-5887.

Lennartz, R.C., Hellems, K.L., Mook, E.R., and Gold, P.E. 1996. Inhibitory avoidance impairments induced by intra-amygdala propranolol are reversed by glutamate but not glucose. Behav. Neurosci. 110: 1033-1039.

Liang, K.C., Bennett, C., and McGaugh, J.L. 1985. Peripheral epinephrine modulates the effects of post-training amygdala stimulation on memory. Behav. Brain Res. 15: 93-100.

Mackintosh, N.J. 1974. The psychology of animal learning. Academic Press, London.

Miranda, M.I., LaLumiere, R.T., Buen, T.V., Bermudez-Rattoni, F., and
McGaugh, J.L. 2003. Blockade of noradrenergic receptors in the basolateral amygdala impairs taste memory. Eur. J. Neurosci. 18: $2605-2610$.

Nader, K. 2003. Memory traces unbound. Trends Neurosci. 26: 65-72.

Parkinson, J.A., Roberts, A.C., Everitt, B.J., and Di Ciano, P. 2005.

Acquisition of instrumental conditioned reinforcement is resistant to the devaluation of the unconditioned stimulus. Q. J. Exp. Psychol. B 58: $19-30$

Przybyslawski, J., Roullet, P., and Sara, S.J. 1999. Attenuation of emotional and nonemotional memories after their reactivation: Role of $\beta$ adrenergic receptors. J. Neurosci. 19: 6623-6628.

Robbins, T.W. and Everitt, B.J. 2002. Limbic-striatal memory systems and drug addiction. Neurobiol. Learn. Mem. 78: 625-636.

Rothemund, Y., Preuschhof, C., Bohner, G., Bauknecht, H.-C., Klingebiel, R., Flor, H., and Klapp, B.F. 2007. Differential activation of the dorsal striatum by high-calorie visual food stimuli in obese individuals. Neuroimage 37: 410-421.

Schechter, M.D. and Calcagnetti, D.J. 1993. Trends in place preference conditioning with a cross-indexed bibliography; 1957-1991. Neurosci. Biobehav. Rev. 17: 21-41.

See, R.E., Grimm, J.W., Kruzich, P.J., and Rustay, N. 1999. The importance of a compound stimulus in conditioned drug-seeking behavior following one week of extinction from self-administered cocaine in rats. Drug Alcohol Depend. 57: 41-49.

Shaham, Y., Shalev, U., Lu, L., de Wit, H., and Stewart, J. 2003. The reinstatement model of drug relapse: History, methodology and major findings. Psychopharmacology 168: 3-20.

Sternberg, D.B., Isaacs, K.R., Gold, P.E., and McGaugh, J.L. 1985. Epinephrine facilitation of appetitive learning: Attenuation with adrenergic receptor antagonists. Behav. Neural Biol. 44: 447-453.

Taylor, J.R. and Robbins, T.W. 1984. Enhanced behavioural control by conditioned reinforcers following microinjections of D-amphetamine into the nucleus accumbens. Psychopharmacology 84: 405-412.

van Stegeren, A.H., Everaerd, W., Cahill, L., McGaugh, J.L., and Gooren, L.J.G. 1998. Memory for emotional events: Differential effects of centrally versus peripherally acting beta-blocking agents. Psychopharmacology 138: 305-310.

Volkow, N.D. and Wise, R.A. 2005. How can drug addiction help us understand obesity? Nat. Neurosci. 8: 555-560.

Wang, G.-J., Volkow, N.D., Thanos, P.K., and Fowler, J.S. 2004. Similarity between obesity and drug addiction as assessed by neurofunctional imaging: A concept review. In Eating disorders, overeating, and pathological attachment to food: Independent or addictive disorders? (ed. Gold, M.S.), pp. 39-53. The Haworth Medical Press, New York.

Wilson, D.A., Pham, T.-C., and Sullivan, R.M. 1994. Norepinephrine and posttraining memory consolidation in neonatal rats. Behav. Neurosci. 108: $1053-1058$.

Winer, B.J. 1991. Statistical principles in experimental design. McGraw-Hill, New York.

Received October 31, 2007; accepted in revised form December 14, 2007. 


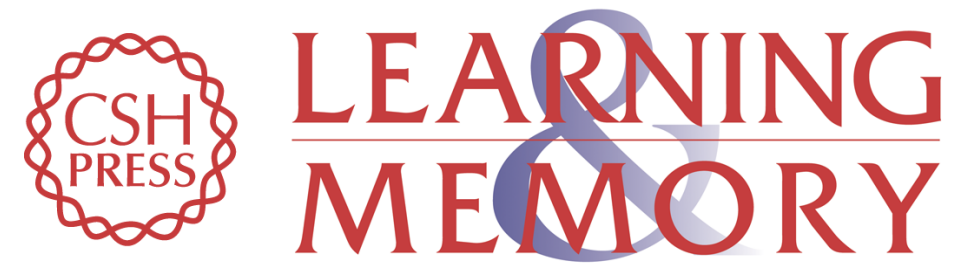

\section{Reconsolidation of appetitive memories for both natural and drug reinforcement is dependent on $\beta$-adrenergic receptors}

Amy L. Milton, Jonathan L.C. Lee and Barry J. Everitt

Learn. Mem. 2008, 15:

Access the most recent version at doi:10.1101//m.825008

References This article cites 41 articles, 3 of which can be accessed free at: http://learnmem.cshlp.org/content/15/2/88.full.html\#ref-list-1

License

Email Alerting Receive free email alerts when new articles cite this article - sign up in the box at the Service top right corner of the article or click here. 